\title{
A comparative study of knowledge and attitudes regarding biomedical waste (BMW) management with a preliminary intervention in an academic hospital
}

Violet N. Pinto, Sumedha M. Joshi, Deepa H. Velankar, Madhavi J. Mankar, Harsh Bakshi, Aasawari Nalgundwar

Department of Community Medicine, Dr. Dnyandeo Yashwantrao Patil Medical College, Nerul, Navi Mumbai, Maharashtra, India

Address for the Correspondence: Dr. Violet N. Pinto,

AVE, Plot 188, Road 33A, Wadala, Mumbai - 400031 , Maharashtra, India. E-mail: violadesa@gmail.com

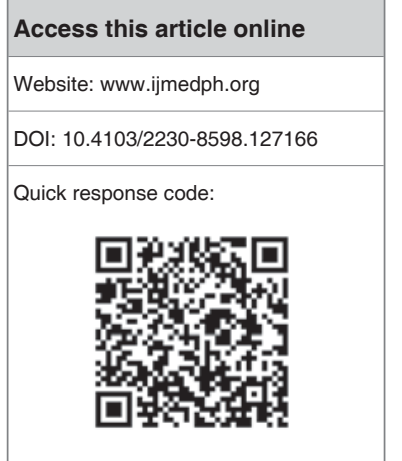

\begin{abstract}
Aims: 1) To assess and compare the knowledge and attitudes regarding biomedical waste (BMW) management in specialists, resident doctors, new medical interns, and final year nursing students. 2) To assess the effectiveness of a training program in changing the knowledge and attitudes regarding BMW management. Study Design: Stage 1-descriptive, Stage 2-quasi-experimental. Participants: Specialists, resident doctors, new medical interns, and final year nursing students. Setting: Tertiary hospital with attached medical college in Navi Mumbai. Data Collection tool: Pretested, precoded self-administered questionnaire. Intervention: Educational training program on BMW management, Period of Study: December 2010-March 2011. Statistical Analysis: Using software Statistical Package for Social Sciences (SPSS) version 20, chi-square, analysis of variance (ANOVA), Tukey's post hoc, and $Z$ tests applied. Results: There was a statistically significant difference in the knowledge scores between the groups as determined by a one-way ANOVA test $(\mathrm{F}(3,226)=11.098, P<0.001)$. A Tukey's post hoc test revealed that the specialists $(20.82 \pm 5.121)$ knowledge scores were significantly higher as compared to resident doctors (16.96 \pm 5.268$)$, medical interns (18.44 \pm 4.293$)$, and nursing group (15.33 \pm 5.144$)$. The positive attitude towards safe management of BMW was not found to be significant. After the training program in the medical interns' a statistically significant increase in their knowledge on BMW management was seen. Conclusion: The knowledge and attitudes between the groups of healthcare personnel varied and was not found to be satisfactory. Training programs with periodical sensitization sessions on BMW management are recommended, especially focusing at the junior level.
\end{abstract}

Key words: Attitudes, assessment, biomedical waste, biomedical waste management, educational intervention, knowledge, training

\section{INTRODUCTION}

Healthcare activities like immunization, diagnostic tests, medical treatments, and laboratory examinations protect and restore health and save lives. At the same time, however, health services may generate large quantity of wastes and by-products that need to be handled safely and disposed of properly. Public concern about medical waste dates back to early 1980's when large quantities of syringes and needles were found on the beaches of the East Coast and in Florida, USA. In India, the concern for medical waste has come to the fore in recent years. The Government of India notified the Biomedical Waste (Management and Handling) Rules in July 1998. "Biomedical waste" (BMW) means any waste, which is generated during the diagnosis, treatment, or immunization of human beings or animals or in research activities pertaining thereto or in the production or testing of biologicals, and including categories mentioned in Schedule $\mathrm{I}^{[1,2]}$ In India, studies have estimated the average hospital waste generation rate ranges between 0.5 and $2.0 \mathrm{~kg} / \mathrm{bed} /$ day and annually about 0.33 million tons of waste are generated. ${ }^{[3]}$ Healthcare workers have an important opportunity to manage the environmental effects of their practices. Their efforts may seem small, but each step builds a base of sound behaviors and thinking that are necessary for the success 
of the whole. ${ }^{[4]}$ Moreover, practices that healthcare personnel begin their career with usually become habits that are difficult to change thereafter. This indicates the importance of addressing BMW management issues amongst health care personnel. Taking this into consideration BMW management was introduced in the undergraduate medical curriculum. The first stage of the current study was conducted to assess the knowledge and attitudes of various groups of healthcare personnel on BMW management, so that we can determine the following: Namely; their existing knowledge and attitudes, whether the undergraduate teaching has had an adequate effect on the knowledge and attitudes of the juniors and if there is a need for a training program in our hospital on BMW management. The second stage of the study was done to assess the effectiveness of a practical oriented training program in changing the knowledge and attitudes, so that it can be introduced as a hospital strategy in the future, if found effective.

\section{MATERIALS AND METHODS}

The study was conducted at a tertiary level hospital and research center with attached medical college in Navi Mumbai. The 232 participants constituted of 52 specialists, 57 resident doctors, 80 new medical interns, and 43 final year nursing students. The study was conducted in two stages. Stage 1 (assessment): After explaining the purpose of the study to each group and taking consent, a pretested and precoded questionnaire was given to them to be filled out. It consisted of various questions to assess their knowledge and attitudes regarding BMW management namely: The problem statement, relevant legislations, hazards, and individuals at potential risk due to improper waste disposal; categorization, segregation procedures, color coding, and recommended waste treatment methods, including waste disposal at rural health center setting, etc. Stage 2 (intervention): An educational training program was conducted for the 80 new medical interns.

A lecture session with power point presentations on various topics of BMW management was taken with demonstrations of BMW equipment, procedures, and color-coded bags, followed by an interactive session. Charts on BMW management were displayed. After the session the questionnaire was readministered to them. The data was analyzed using software Statistical Package for Social Sciences (SPSS) version 20. The knowledge responses were allotted scores (correct and 75\% correct responses $=1$, incorrect $/$ blank response $=0$ ). Chi square, one-way ANOVA, Tukey's post hoc test and test of significance between two proportions ( $\mathrm{Z}$ test) were applied. Approval of the institutional ethics committee was taken prior to the commencement of the study.

\section{RESULTS}

Tables 1 and 2 show the percentage-wise knowledge and knowledge scores, respectively of the participants on various

\begin{tabular}{|c|c|c|c|c|c|c|c|c|}
\hline \multirow{2}{*}{$\begin{array}{l}\text { Knowledge on BMW } \\
\text { Management Elements }\end{array}$} & \multicolumn{2}{|c|}{ Specialists (52) } & \multicolumn{2}{|c|}{ Resident Doctors (57) } & \multicolumn{2}{|c|}{ Medical Interns (80) } & \multicolumn{2}{|c|}{ Nursing students (43) } \\
\hline & $\begin{array}{c}\text { Correct } \\
\text { respondents } \\
(N)\end{array}$ & $\%$ & $\begin{array}{l}\text { Correct } \\
\text { respondents } \\
(N)\end{array}$ & $\%$ & $\begin{array}{c}\text { Correct } \\
\text { respondents } \\
(N)\end{array}$ & $\%$ & $\begin{array}{l}\text { Correct } \\
\text { respondents } \\
(N)\end{array}$ & $\%$ \\
\hline Relevant legislations & 15 & 28.8 & 8 & 14.0 & 11 & 13.8 & 5 & 11.6 \\
\hline $\begin{array}{l}\text { Hazards caused by improper } \\
\text { disposal }\end{array}$ & 41 & 78.8 & 43 & 75.4 & 70 & 87.5 & 35 & 81.4 \\
\hline $\begin{array}{l}\text { Individuals at potential risk due } \\
\text { to improper disposal }\end{array}$ & 48 & 92.3 & 41 & 71.9 & 62 & 77.5 & 25 & 58.1 \\
\hline $\begin{array}{l}\text { Classified BMW according to } \\
\text { categories ( } 1 \text { to } 10)\end{array}$ & 30 & 57.7 & 15 & 26.3 & 21 & 26.2 & 11 & 25.6 \\
\hline $\begin{array}{l}\text { Matched BMW category with } \\
\text { appropriate color coded bag }\end{array}$ & 30 & 57.7 & 28 & 49.1 & 25 & 31.2 & 23 & 53.5 \\
\hline $\begin{array}{l}\text { Identified symbol for } \\
\text { biohazardous waste }\end{array}$ & 50 & 96.2 & 52 & 91.2 & 59 & 73.8 & 23 & 53.5 \\
\hline $\begin{array}{l}\text { Identified disposal/ treatment } \\
\text { method }\end{array}$ & 44 & 84.6 & 39 & 68.4 & 50 & 62.5 & 37 & 86 \\
\hline $\begin{array}{l}\text { Identified BMW disposal method } \\
\text { at rural setting }\end{array}$ & 30 & 57.7 & 21 & 36.8 & 21 & 26.2 & 8 & 18.6 \\
\hline
\end{tabular}

\begin{tabular}{|c|c|c|c|c|c|c|}
\hline Groups & $N$ & Mean & Standard deviation & Standard error & $\mathbf{F}$ & Significance \\
\hline Specialists & 52 & 20.83 & 5.121 & 0.710 & 11.098 & 0.000 \\
\hline Resident Doctors & 57 & 16.96 & 5.268 & 0.698 & & \\
\hline Medical Interns & $78(-2)$ & 18.44 & 4.293 & 0.486 & & \\
\hline Nursing students & 43 & 15.33 & 5.144 & 0.784 & & \\
\hline Total & 230 & 18.03 & 5.212 & 0.344 & & \\
\hline
\end{tabular}

One-way analysis of variance (ANOVA) test applied 
aspects of BMW management. There was a statistically significant difference between the groups as determined by one-way ANOVA $(\mathrm{F}(3,226)=11.098, P<0.001)$. A Tukey's post hoc test revealed that specialists average knowledge scores were statistically significantly higher $(20.82 \pm 5.121)$ as compared to resident doctors (16.96 \pm 5.268$)$, medical interns (18.44 \pm 4.293$)$, and nursing group $(15.33 \pm 5.144)$. The scores of medical interns were significantly more than the nursing group. There were no statistically significant differences between the resident doctors and interns, resident doctors and nursing groups.

There was no statistically significant difference in the attitudes of the four groups towards safe management of BMW [Table 3]. The attitude question of "Which health care staff is responsible for segregation of BMW?" was a multiple response question. Forty-four (77.2\%) resident doctors, 31 (49.6\%) specialists, 17 (21.2\%) interns, and four $(9.3 \%)$ nurses felt that only auxillary staff is responsible for the segregation of BMW.
Tables 4 and 5 show the medical interns change in the knowledge and attitudes, respectively, preintervention versus postintervention. After the educational session, $61.2 \%$ of the interns were able to enumerate four or more hazards of improper waste disposal namely infection of hospital staff, patient infection, needle stick injuries, and environmental pollution. Other hazards also mentioned were radioactivity and genetic changes. With regards to individuals at potential risk besides hospital staff and patients, $53(66.2 \%)$ also mentioned ragpickers posttest, compared to only 20 (25\%) pretest. Seventeen $(21.2 \%)$ pretest had felt that 'it was the responsibility of only the auxiliary staff', which decreased to nine (11.2\%) posttest.

\section{DISCUSSION}

The waste produced in the course of healthcare activities carries a higher potential for infection and injury than any other type of waste. ${ }^{[5]}$ Its improper disposal can have direct and indirect health impacts as well as pose a potential threat to the surrounding environment, persons handling it, and the public in general.

\begin{tabular}{|c|c|c|c|c|c|c|c|c|c|}
\hline \multirow{2}{*}{$\begin{array}{l}\text { Attitudes on safe } \\
\text { management of } \\
\text { biomedical waste (BMW) }\end{array}$} & \multicolumn{2}{|c|}{ Specialists (52) } & \multicolumn{2}{|c|}{ Resident doctors (57) } & \multicolumn{2}{|c|}{ Medical interns (80) } & \multicolumn{2}{|c|}{ Nursing students (43) } & \multirow{2}{*}{$\begin{array}{c}\text { Chi-square } \\
\text { test } \\
(P \text {-value })\end{array}$} \\
\hline & $\begin{array}{c}\text { Positive } \\
\text { responses }(N)\end{array}$ & $\%$ & $\begin{array}{c}\text { Positive } \\
\text { responses }(N)\end{array}$ & $\%$ & $\begin{array}{c}\text { Positive } \\
\text { responses }(N)\end{array}$ & $\%$ & $\begin{array}{c}\text { Positive } \\
\text { responses }(N)\end{array}$ & $\%$ & \\
\hline $\begin{array}{l}\text { All healthcare staff are } \\
\text { responsible for segregation }\end{array}$ & 32 & 61.5 & 40 & 70.2 & 60 & 75 & 35 & 81.4 & 0.16 \\
\hline $\begin{array}{l}\text { It is the responsibility of } \\
\text { government }\end{array}$ & 37 & 71.2 & 46 & 80.7 & 59 & 73.8 & 26 & 60.5 & 0.16 \\
\hline $\begin{array}{l}\text { It increases financial burden } \\
\text { on hospital management }\end{array}$ & 16 & 30.8 & 18 & 31.6 & 21 & 26.2 & 8 & 18.6 & 0.47 \\
\hline It is an extra burden on work & 6 & 11.5 & 13 & 22.8 & 8 & 10 & 3 & 7 & 0.07 \\
\hline $\begin{array}{l}\text { Feel the need to attend } \\
\text { educational program on } \\
\text { BMW management }\end{array}$ & 41 & 78.8 & 44 & 77.2 & 74 & 92.5 & 32 & 74.4 & 0.03 \\
\hline
\end{tabular}

\begin{tabular}{|c|c|c|c|c|c|}
\hline \multirow[t]{2}{*}{ Knowledge on BMW Management } & \multicolumn{2}{|c|}{ Pre-intervention } & \multicolumn{2}{|c|}{ Post-intervention } & \multirow{2}{*}{$\begin{array}{c}\mathrm{Z} \text { test } \\
(P \text { value })\end{array}$} \\
\hline & $\begin{array}{c}\text { Correct } \\
\text { respondents }(N)\end{array}$ & $\%$ & $\begin{array}{c}\text { Correct } \\
\text { respondents }(N)\end{array}$ & $\%$ & \\
\hline Relevant legislations & 11 & 13.8 & 53 & 66.2 & 0.004 \\
\hline Enlisted $\geq 4$ hazards caused by improper disposal & 22 & 27.5 & 49 & 61.2 & 0.018 \\
\hline Individuals at potential risk due to improper disposal & 62 & 77.5 & 78 & 97.5 & 0.0001 \\
\hline Classified BMW according to categories (1 to 10 ) & 21 & 26.2 & 64 & 80 & 0.0001 \\
\hline Matched BMW category with appropriate color coded bag & 25 & 31.2 & 55 & 68.8 & 0.004 \\
\hline Identified symbol for biohazardous waste & 59 & 73.8 & 80 & 100 & 0.0001 \\
\hline Identified disposal/treatment method & 50 & 62.5 & 71 & 88.8 & 0.001 \\
\hline Identified BMW disposal method at rural setting & 21 & 26.2 & 66 & 82.5 & $<0.001$ \\
\hline
\end{tabular}

\begin{tabular}{|c|c|c|c|c|c|}
\hline \multirow{2}{*}{$\begin{array}{l}\text { Attitudes on safe management } \\
\text { of healthcare waste }\end{array}$} & \multicolumn{2}{|l|}{ Preintervention } & \multicolumn{2}{|l|}{ Postintervention } & \multirow[t]{2}{*}{$\mathrm{Z}$ test (P-value) } \\
\hline & Positive responses $(N)$ & $\%$ & Positive responses $(N)$ & $\%$ & \\
\hline All healthcare staff are responsible of segregation & 60 & 75 & 76 & 95 & 0.002 \\
\hline It is only responsibility of the government & 59 & 73.8 & 52 & 65 & 0.424 \\
\hline It increases financial burden on management & 21 & 26.2 & 20 & 25 & 0.787 \\
\hline It is an extra burden on work & 8 & 10 & 4 & 5 & 0.111 \\
\hline
\end{tabular}


In the current study the specialists overall, had the best knowledge as compared to the other groups regarding the various aspects of BMW management [Tables 1 and 2]. The correct respondents in the specialists on the various BMW management elements, that is, hazards caused by improper disposal, individuals at risk, etc., ranged from 57.7 to $96.2 \%$. Sharma and Chauhan ${ }^{[6]}$ in their study observed that $77.78 \%$ specialists had awareness regarding BMW management and handling rules. In their study Saini et al., ${ }^{[7]}$ reported that $85 \%$ specialists had knowledge of the BMW management rules. In the study by Yadavannavar et al. ${ }^{[8]}$ the teaching staff gave more correct responses $(97.4 \%)$ to questions on BMW management as compared to the nonteaching staff $(80 \%)$.

$75.4 \%$ residents and $87.5 \%$ interns responded correctly on hazards caused by improper disposal [Table 1]. In the study by Basu et al., ${ }^{[0]}$ $98.8 \%$ junior doctors had perceptions about different health problems due to BMW.

In our study, correct responses with regards to BMW categories were given by $26.3 \%$ residents and $26.2 \%$ interns and $49.1 \%$ residents, and $31.2 \%$ interns had correct knowledge about color coding bags [Table 1]. Whereas in the study by Basu et al., ${ }^{[9]}$ the awareness of the junior doctors about waste categories and color coding bags was higher, that is, 55.9 and $76.4 \%$, respectively. Pandit et al., ${ }^{[10]}$ in their study observed that not a single doctor knew about the various categories of BMW.

91.2\% residents and $73.8 \%$ interns in our study knew about the biohazard symbol, while $68.4 \%$ residents and $62.5 \%$ interns were able to correctly identify BMW disposal/treatment methods [Table 1]. In the study by Basu et al., ${ }^{[9]}$ the awareness of the junior doctors about the biohazard symbol and various methods of disposal of BMW were 69.7 and $29.5 \%$, respectively. Saini et al. ${ }^{[7]}$ reported that $81 \%$ residents had knowledge on BMW management rules.

The resident doctors and medical interns had more knowledge of the theoretical aspects (individuals at risk, biohazard symbol, waste disposal method at rural health center, etc.) of BMW management as compared to the nursing group, which could be attributed to the fact that they are taught this topic in their undergraduate curriculum as well as oriented on the hospital and rural health center BMW disposal as part of their visits in community medicine. A higher percentage in the nursing group correctly matched biomedical waste categories with appropriate color-coded bags and identified the disposal methods per category as compared to the medical interns and resident doctors [Table 1]. The nursing students probably had more knowledge of the practical aspects as they frequently worked in the wards.

There was no statistically significant difference between the attitudes of all the groups. The attitude question of "Which healthcare staff is responsible for segregation of BMW?" was a multiple response question. Only $40(70.2 \%)$ resident doctors, $32(61.5 \%)$ specialists, and $60(75 \%)$ interns as compared to 35
$(81.4 \%)$ nurses felt that all healthcare staff is responsible for segregation [Table 3]. A small percentage of doctors had expressed it is not their duty to find out whether a sensible approach to BMW management is required or not and BMW management is the responsibility of the administration and sanitary staff and not the doctors. The residents had the least favorable attitude towards BMW management as compared to the other groups; $22 \%$ of them felt that it was an extra burden, $31.6 \%$ felt it increases the financial burden of hospital management, and $80.7 \%$ felt it was only the responsibility of the government, as compared to the other groups. The attitude of medical group in general towards the issue of BMW management was positive, but the responsibility for the same was not acknowledged as much by them as compared to the nursing group. Saini et al., ${ }^{[7]}$ in their study observed that with regards to questions on attitude towards scientific processes of BMW management nurses scored $95-100 \%$ as compared to $63-96 \%$ in resident doctors.

With regards to the attitude question on 'Would you like to attend a program on BMW management?', the medical interns had the most positive attitude, $92.5 \%$. Hence, the educational training session was given to this group first. After the training program (Stage 2 of study) a significant increase in the medical interns knowledge with regards to the more detailed practical as well as theoretical aspects of BMW management was seen [Table 4]. The interns $(61.2 \%)$ were able to enumerate four or more hazards of improper waste disposal namely infection of hospital staff, patient infection, needle stick injuries, and environmental pollution. In the study by EL-Sharkawy ${ }^{[11]}$ significant improvement of good knowledge from 25 to $78 \%$ in the internship physicians, was seen after the educational intervention. In the study by El Sayed et al., ${ }^{[12]}$ also, a statistically significant improvement in the nurses' knowledge and practices about healthcare waste management, was seen after introduction of the intervention program.

In our study there was increased public sensitivity in the medical interns after the training program. While enlisting individuals at potential risk, besides hospital staff and patients, $53(66.2 \%)$ interns in the posttest also mentioned ragpickers compared to only $20(25 \%)$ in pretest. Also, $17(21.2 \%)$ who had felt that it was the responsibility of only the auxillary staff in pretest, decreased to nine $(11.2 \%)$ in posttest. In the study by EL-Sharkawy ${ }^{[11]}$ good attitude improvement postintervention was from 11.2 to $30.6 \%$.

Attitude change of the interns towards BMW management issues in the posttest results were not significant [Table 5]. This could be the case as usually a longer time period is required to assess attitude change.

To sum up, we found varied levels of knowledge and attitudes amongst all our groups which were not found to be satisfactory. The better knowledge in the specialists could be attributed to the fact that they had more years of experience in hospital practice and procedures and had access to government notifications (BMW rules and amendments) as a part of their administrative duties. 
They are also involved in the teaching of BMW management to the undergraduates. However, their own responsibility in the chain of safe waste management was not acknowledged by them. Their positive attitude could play an important role in motivating the juniors of their respective departments. Even though this topic had been taught to the residents and interns in their undergraduate curriculum, they did not have adequate knowledge. The lack of positive attitude in the residents is a matter of concern considering that they will be starting their practice in the near future. There were lacunae in the knowledge of the nursing group also. The training program and periodical sensitization sessions on BMW management will be needed for motivation and change in mindset of all the healthcare personnel especially those in the junior level. Limitations/factors not included in the scope of the current study were: Assessment of other groups like senior nurses, auxillary staff, etc.; BMW management practices assessment, training program for all the groups, and longer period for attitude change assessment.

\section{CONCLUSION}

The knowledge and attitudes of the medical and nursing groups regarding BMW management varied and were not found to be satisfactory. A strategy consisting of a practical oriented training program along with periodical sensitization sessions regarding safe management of BMW for the all healthcare personnel was found necessary especially focusing at the junior level.

\section{REFERENCES}

1. World Health Organization. [Internet] Safe Management of Bio- medical Sharps Waste in India: A Report on Alternative Treatment and Non-Burn Disposal Practices. New Delhi: WHO/SEARO; c 2005, [p 1]. Available from: http://www.searo.who.int/LinkFiles/SDE_SDE_mgmt-bio-medical intro.pdf SEA-EH-548 [Last cited 2013 May 15].
2. The Gazette of India. Ministry of Environment and forest notification on the Bio-medical Waste (Management and Handling) Rules 1998. New Delhi; 1998, Available from: http://www. delhigovt.nic.in/dept/health/ bmwcom.pdf [Last cited 2013 May 15].

3. Patil AD, Shekder AV. Health-care waste management in India. J Environ Manage 2001;63:211-20.

4. McVeigh P. OR nursing and environmental ethics. Medical waste reduction, reuse and recycling. Todays OR Nurse 1993;15:13-18.

5. Park K. Hospital waste management. In: Park's Text book of Preventive and Social Medicine. $21^{\text {st }}$ ed. Chp.14. Jabalpur: M/s Banarsidas Bhanot Publishers; 2011. p. 730.

6. Sharma S, Chauhan SV. Assessment of bio-medical waste management in three apex Government hospitals of Agra. J Environ Biol 2008;29:159-62.

7. Saini S, Nagarajan SS, Sarma PK. Knowledge, attitude and practices of biomedical waste, management among staff of a tertiary level hospital in India. J Acad Hosp Admin 2005;17:1-12.

8. Yadavannavar M, Berad AS, Jagiradar P. Biomedical waste management: A study of knowledge, attitude and practices in tertiary health care institution in Bijapur. Indian J Community Med 2010;35:170-1.

9. Basu M, Das P, Pal R. Assessment of future physicians on biomedical waste management in a tertiary care hospital of West Bengal. J Nat Sc Biol Med 2012;3:38-42.

10. Pandit NB, Mehta HK, Kartha GP, Choudhary SK. Management of biomedical waste: Awareness and practices in a district of Gujarat. Indian J Public Health 2005;49:245-7.

11. El-Sharkawy GF. Effect of an educationl programme about medical waste management on awareness of internship physicians in Zagazig University hospitals. Zagazig J Occup Health Safety 2009;2:10-16.

12. El Sayed HS, Zakaria MA, Gheith NA. Intervention program for nurses about health care waste management. Res J Med Med Sci 2012;7:25-3

How to cite this article: Pinto VN, Joshi SM, Velankar DH, Mankar MJ, Bakshi H, Nalgundwar A. A comparative study of knowledge and attitudes regarding biomedical waste (BMW) management with a preliminary intervention in an academic hospital. Int J Med Public Health 2014;4:91-5.

Source of Support: Nil, Conflict of Interest: None declared. 